\title{
Pharmaceutical Care Training Increases the Ability Pharmacists to Reduce the Incidence of Medication Error By Akrom
}




\title{
5 \\ Pharmaceutical Care Training Increases the Ability Pharmacists to Reduce the Incidence of Medication Error
}

\author{
Akrom, Budiyono, Woro Supadmi \\ 3 \\ Faculty of Pharmacy, Universitas Ahmad Dahlan, Yogyakarta, Indonesia
}

\begin{tabular}{l} 
Article Info \\
\hline Article history: \\
Received Feb 10, 2015 \\
Revised Apr 20, 2015 \\
Accepted May 16, 2015 \\
\hline
\end{tabular}

Keyword:

Medication Error

Pharmaceutical Care

Pharmacist Interventions

Training

\begin{abstract}
The objective of the study was to know the potential incidence of medication errors before and after the training of pharmaceutical care in the Outpatient Pharmacy Unit of general privat hospital in rural area of Yogyakarta. The observational studi used to describe the potential medication errors in prescribing phase and dispensing phase and to determine its completion. This research was conducted prior to the training of pharmaceutical care that is in May and after the training of pharmaceutical cares that was in June 2014 at the Outpatient Unit of general privat hospital in rural area Yogyakarta. The data was taken from a book review of prescriptions in outpatient units for the month. The results showed that the number of potential medication errors before the training of pharmaceutical care in prescribing phase (prescribing errors) found 17 cases or $0.21 \%$ and the dispensing phase (dispensing error) as many as 36 cases or $0.45 \%$. While the potential for medication errors after the training phase of pharmaceutical care in prescribing phase (prescribing error) is found as many as 115 cases or $1.45 \%$ and the dispensing phase (dispensing error) is found as many as 165 cases or $2.10 \%$.
\end{abstract}

Copyright (C) 2015 Institute of Advanced Engineering and Science. All rights reserved.

\section{Corresponding Author:}

Akrom,

Department of Pharmacology and Clinical Pharmacist,

Pharmacy Faculty of Universitas Ahmad Dahlan,

Jalan Prof. Dr. Soepomo, S.H., Janturan, Warungboto, Umbulharjo 55612, Yogyakarta, Indonesia.

Email : akmaa_uad@yahoo.co.id

\section{INTRODUCTION}

Medication error is one of curren publ 2 health problem. Self medication or hospital drug using contributed to medication error in community. The National Coordinating Council for Medication Error Reporting and Prevention (NCC MERP) reported that approximately 0.1 million people die annually from medical errors that occur in hospitals and the resulting death toll/year due to medication errors is higher than that of work place injuries [1].

Medication error is any life-threatening events that could be prevented. Data medication error events in the world continue to increase. In the United States, incidence of medication errors between $2-14 \%$ of patients with $1-2 \%$ which led to a loss of patients usually occurs because the process of prescribing is wrong. Medication error is estimated to result in 7,000 patients die each year in the US [2].

The incidence of medication errors in Indonesia has not been recorded accurately and systematically but medication errors are fairly common in health care institutions. At the hospital, medication errors reported 3 to $6.9 \%$ in patients hospitalized. The incidence of errors due to errors in drug order also varies, which is between 0.03 to $16.9 \%$. 8 ne researcher found that $11 \%$ of medication errors in hospitals associated with an error when submitting the drug to the patient in the form of the dose or the wrong medicine. However, despite the relatively frequent medication errors are generally rare that ended with an injury in the patients [3].

3

Journal homepage: http://iaesjournal.com/online/index.php/IJPHS 
Outpatient unit (OPU) is one of the crucial departement of the occurrence of medication errors. It is because the patient will use the medicine itself and without the supervision of health workers, as opposed to inpatient where patients will be monitored closely in order to achieve optimal therapeutic purposes. Pharmacists as one of the health workers have a strategic role in addressing medication errors, especially (4) ated to prescribing and dispensing error. One of way that the pharmacist contributes is by doing a pharmaceutical care [4].

Pharmaceutical care is the responsible provision of drug therapy for the purpose of achieving definite outcomes that improve or maintain a patient's quality of life (Weidenmayer et. all, 2006). Gillespie (2012) states that patients who have received a comprehensive pharmacist intervention have fewer visits to the hospital and can save costs. Pharmacist intervention also significantly improves the suitability of the recipe [5].

The ability to implement pharmaceutical care requires adequate knowledge of the drug therapy goals. It also takes skill and a high willingness to implement them. Screening recipe as one part of pharmaceutical care must be in 1 lemented properly. Therefore, it is necessary to study the potential of medication errors that occur in general privat hospital in rural area in 1 ggyakarta to describe the error in order to do proper repair. The purpose of this study was to determinate the potential of medication errors in 1 escribing phase and dispensing phase in Outpatient general privat hospital in rural area in Yogyakarta before and after the training of pharmaceutical care as well as to determinate the problem solving related to medication error.

\section{RESEARCH METHOD}

This study was an observational study with a survey method. This study was conducted at Outpatient of general privat hospital in rural area in Yogyakarta, during May and June 2014. The instruments used in this research were form review of prescription, book review of prescription and Form of data processing. Objects were whole recipe of the outpatient general privat hospital in rural area in Yogyakarta in May and1in June 2014. The course of study began by conducting a preliminary study to see whether or not there was the potential for medication errors in prescribing phase and dispensing phase. Then, after the obtained results, it followed by retrieval of prior data to the training (May 2014) and after the training (June 2014).

1 The data derived from the form review of prescription and book review of prescription in Outpatient general privat h1 1 pital in rural area in Yogyakarta. After the data was obtained then the data was performed analsisis to see the potential for medication errors in prescribing phase and dispensing phase. Furthermore, the prescribing phase errors were grouped into overdose, underdose, wrong direction, duplication, wrong duration of treatment, contraindications, indications without drugs, drugs without indication, compliance problem, wrong patient, side effects potential, drug interactions, wrong of the strengths dosage, wrong dosage forms and drug availability. While the dispensing phase errors were grouped into misread the orders, wrong preparation, and wrong labele. The data was obtained then presented descriptively in tables and percentages.

\section{RESULTS AND ANALYSIS}

\subsection{Prescribing Errors}

\subsubsection{The Number of Prescribing Errors before and after training}

Table 1 provides information that the detection of the prescriptions error before the training of pharmaceutical care as much as 17 recipes or $0.21 \%$ and after training of pharmaceutical care as much as 115 recipes or $1.47 \%$.

Table 1. Prescribing errors Before and After Training Pharmaceutical Care at Outpatient general privat

\begin{tabular}{ccc}
\multicolumn{3}{c}{ hospital in rural area in Yogyakarta } \\
\hline & Number of recipe & Prescribing error \\
\hline Before Training & 8068 & $17(0.21 \%)$ \\
After Training & 7847 & $115(1.47 \%)$ \\
\hline
\end{tabular}

Potential medication errors associated with incorrect prescribing (prescribing error) after training increased more than $600 \%$. It can be caused as a result of pharmaceutical care training conducted by 
Pharmacist Departement. So pharmacists increased awareness or concern for the prevention of medication errors and understand how to identify relevant potential medication errors that can result in treatment failure.

\subsubsection{Types of Prescribing Errors}

Table 2 describes the most potential errors that can be identified by pharmacist before the pharmaceutical care training is overdose.

Table 2. Type of Prescribing error before and after pharmaceutical care training at Outpatient general privat hospital in rural area in Yogyakarta

\begin{tabular}{lcc}
\hline \multicolumn{1}{c}{ Type of Error } & \multicolumn{2}{c}{ Number Error } \\
\cline { 2 - 3 } & Before Training & After Training \\
\hline Duplication & $1(5.88 \%)$ & $26(22.61 \%)$ \\
Compliance problem's & $0(0 \%)$ & $17(14.78 \%)$ \\
Wrong Direction & $2(11.76 \%)$ & $14(12.17 \%)$ \\
Underdose & $3(17.65 \%)$ & $11(9.57 \%)$ \\
Overdose & $7(41.18 \%)$ & $9(7.83 \%)$ \\
Indications without drugs & $0(0 \%)$ & $8(6.96 \%)$ \\
Adverse drugs reaction & $0(0 \%)$ & $8(6.96 \%)$ \\
Drug Interaction & $0(0 \%)$ & $7(6.09 \%)$ \\
Wrong Duration & $0(0 \%)$ & $5(4.35 \%)$ \\
Strenghts Formulation & $0(0 \%)$ & $3(2.61 \%)$ \\
Dosage form & $0(0 \%)$ & $3(2.61 \%)$ \\
Contraindications & $2(11.76 \%)$ & $2(1.74 \%)$ \\
Wrong Patients & $1(5.88 \%)$ & $1(0.87 \%)$ \\
Availability & $0(0 \%)$ & $1(0.87 \%)$ \\
Drugs without indication & $1(5.88 \%)$ & $0(0 \%)$ \\
Total error & $17(100 \%)$ & $115(100 \%)$ \\
\hline
\end{tabular}

For example, patients with skin infections caused by traffic accidents get prescription oral ciprofloxacin $500 \mathrm{mg}, 1$ tablet q24hr; as knowed that a dose of oral ciprofloxacin is $250 \mathrm{mg}-500 \mathrm{mg} \mathrm{q} 12 \mathrm{hr}$ Some types of errors before training of pharmaceutical care is not found such compliance problem's, indications without drug, adverse drug reaction, interactions, duration, strengths formulation, dosage form, and the availability of drugs. The absence of findings of the error can be caused by lack of knowledge of pharmacist. While after the training, detection of potential prescribing errors are most drug duplication that occurred in 26 cases. Duplication occured because the patient is still had medicine at home, but given the same drug. It was otherwise identified by pharmacists and overcome so could lead to patients using the same drugs that result in overdose.

Precribing error is most common in medication error incidence in out patients hospital in public hospital, in Yogyakarta [4]. Medication errors have been conceptualized based on causes, outcomes, and stages of the medication delivery process. Research shows that prescribing errors have contributed the most in the occurrence of errors, which is $39 \%$ due to lack of knowledge about prescribed medications, less build relationships with patients, slips, or miscalculation. Transcription and verification take $12 \%$ of the errors are mainly due to the inability to read the recipe. Miscalculation, mistake preparation, and distribution of errors contribute to the $11 \%$ error for dispensing phase. And finally, $38 \%$ error occurred in the administration phase, which is caused mainly due to the similar packaging, re-check failure, the failure to understand the drug dose, direction of treatment is not clear, and the shortage of officers[7]. A study in a teaching hospital in Malaysia to provide data that from entering outpatient prescription amounts to 6340 for one week, there are 43 recipes that require pharmaceutical intervention is problematic due to the recipe. The problem consists of completeness prescription, wrong drug, wrong dose, and wrong potential drug.

\subsection{Dispensing Error}

Dispensing errors are the fault of the officer at the time of the reading prescription (misread order), drug preparation, and labeling / drug etiquette. It will cause errors in dispensing medication errors, which in turn can lead to treatment failure. Here is the importance of dispensing medication properly.

Table 3 describes the most identification of potentially medication errors by pharmaceutical services (dispensing error). Dispencing error before training were as much as 36 cases or $0.45 \%$ and after the training were as much as 165 cases or $2.10 \%$. An average every day there were 3 cases that the potential for dispensing errors found by the pharmacist. 
Table 3. Dispensing errors Before and After Training Pharmaceutical Care at Outpatient general privat hospital in rural area in Yogyakarta

\begin{tabular}{lcc}
\hline & Number of recipe & Prescribing error \\
\hline Before Training & 8068 & $36(0.45 \%)$ \\
After Training & 7847 & $165(2.10 \%)$ \\
\hline
\end{tabular}

It is seen the increasing identification of potential dispensing error incidence because of the increased awareness of the pharmacist in understanding the potential of medication errors that could occur in the pharmaceutical service. This could be due to increased awareness of the effects of pharmaceutical care training that were followed by a pharmacist.

\subsubsection{Types of Dispensing Errors}

Table 4 describes that the most findings of events that could potentially cause a dispensing error before training is preparation of the drug that is as many as 19 cases or $52.78 \%$.

Table 4. Types of dispensing error before and after training Pharmaceutical Care at Outpatient general privat hospital in rural area in Yogyakarta

\begin{tabular}{lcc}
\hline \multirow{2}{*}{ Type Error } & \multicolumn{2}{c}{ Number } \\
\cline { 2 - 3 } \multicolumn{1}{c}{ Before the training } & After the training \\
\hline Misreading & $9(25.00 \%)$ & $31(18.79 \%)$ \\
Preparation & $19(52.78 \%)$ & $52(31.52 \%)$ \\
Labeling & $8(22.22 \%)$ & $82(49.70 \%)$ \\
Total error & $36(100 \%)$ & $165(100 \%)$ \\
\hline
\end{tabular}

While after the training, the type of error which was most commonly found was 82 cases or $49.70 \%$ in the labeling. For example, patients received a novomix recipe (insulin mixture) then were read by the pharmacist as novorapid (fast action of insulin). If this was not observed properly, it would cause very harmful effects where novorapid was rapidly acting insulin post prandial while novomix was a mixture of insulin used to treat post-prandial glucose and fasting glucose.

\subsubsection{Completion of Potential Medication error}

Table 5 described the intervention by pharmacists in resolving problems associated with the potential of medication errors before the training of pharmaceutical care was a way to confirm to the doctor.

Table 5. Pharmacist Intervention for Potential Before and After Training Pharmaceutical Care at Outpatient general privat hospital in rural area in Yogyakarta

\begin{tabular}{lcc}
\hline \multirow{2}{*}{ Types of Intervention } & \multicolumn{2}{c}{ Number } \\
\cline { 2 - 3 } & Before The Training & After The Training \\
\hline Confirmation to the doctor & $17(100 \%)$ & $66(57.39 \%)$ \\
Information and Education & $0(0 \%)$ & $41(35.65 \%)$ \\
Counseling & $0(0 \%)$ & $3(2.61 \%)$ \\
Other interventions & $0(0 \%)$ & $5(4.35 \%)$ \\
Totals & $17(100 \%)$ & $115(100 \%)$ \\
\hline
\end{tabular}

While after the training, pharmacist interventions in addressing potential medication errors were to confirm to the doctor with a number of 66 cases $(57.39 \%)$, information and education 41 cases $(35.65 \%)$, counseling 3 cases $(2.61 \%)$ and other interventions as much as 5 cases $(4.35 \%)$. Other interventions conducted among canceled therapy from a doctor but were not with confirmation. Cancellation therapy or changeed of doses should not be made unilaterally by the pharmacist as possible to the doctor to have another purpose. Pharmacist supposed the docto 1 to confirm that the problem could be solved together.

The results showed that the pharmaceutical care training increases the ability of pharmacists to preventing the incidence of medication errors in one of the private hospitals in rural areas in Yogyakarta. Pharmaceutical care training is proven to increase the ability of pharmacists in identifying the incidence of medication errors either in prescribing phase or dispensing phase. Pharmacist interventions related potential

IJPHS Vol. 4, No. 2, June 2015 : $119-123$ 
medication errors before the pharmaceutical care training wereby way to confirm to the doctor while after the pharmaceutical care training were by way of confirmation to the doctor, the provis $2 \mathrm{n}$ of drug information and patient education, medication counseling and activities / other interventions.A medication can be a blessing if the healthcare provider prescribes, dispenses and administers drugs to patients correctly [8].

\section{CONCLUSION}

Potential Medication errors in prescribing phase (prescribing error) before the training of pharmaceutical care were found in 17 cases or $0.21 \%$ and after the training were found as many as in 115 cases or $1.45 \%$. Potential medication errors in dispensing phase (dispensing error) before training of pharmaceutical care were found as many as in 36 cases or $0.45 \%$ and after the training were found as many as in 165 cases or $2.10 \%$. Completion of the problems associated with medication errors before the training was by way of confirmation to the doctor while after the training were by way of confirmation to the doctor, giving information \& patient education, patient counseling and other interventions.

\section{RECOMENDATION}

From the results of this study could be used as a reference that the need for pharmaceutical care training for pharmacists in hospitals to reduce the incidence of medication errors.

\section{ACKNOWLEDGEMENTS}

Acknowledgements and awards granted to directors and medical staff at RSU PKU Muhammadiyah Yogyakarta. They have given permission so that research can be done.

\section{REFERENCES}

[1] National Coordinating Council for Medication Error Reporting and Prevention, "Medication errors", 2014. From http://www.nccmerp.org/ [January 6, 2014)

[2] Dwiprahasto I., "Interventions Training to Minimize Risk of Medication errors in Primary Health Care Center", Journal of Medical Sciences, vol/issue: XXXVIII(1), 2006. From: http://i-lib.ugm.ac.id/jurnal/detail .php? dataId = 5603 [January 6, 2014]

[3] Williams DGT., "Medication errors", JR Coll Physicians Edinb, pp. 343-346, 2007.

[4] Perwitasari D., Jamiul A., Wahyuningsih I., "Medication error In Out patients of government hospital in Yogyakarta", International Journal of Pharmaceutical Sciences Review and Research, vol/issue: 1(1), pp. 002, 2010 .

[5] Gillespie U., "Effect of Clinical Pharmacists Intervention. Department of Pharmaceutical Bioscienses", Uppsala University, Sweden, 2012.

[6] Ni KM., Spot CS., Ramli MNB., "Outpatient Prescription Intervention Activities by Pharmacy in a Teaching Hospital", Malaysian Journal of Pharmacy, 2003.

[7] Shah A., "Pharmacy Intervention in medication-use process", the University of Manitoba, Winnipeg, Canada, 2010

[8] Wiedenmayer K., Summers RS., Mackie CA., Gous AGS., Everard M., Tromp D., "Developing pharmacy practice: A focus on patient care Handbook- 2006 edition", World Health Organization, Department of Medicines Policy and Standards. Den Haag :WHO/FIP, 2006

Pharmaceutical Care Training Increases the Ability Pharmacists to Reduce the Incidence .... (Akrom) 
Pharmaceutical Care Training Increases the Ability Pharmacists to Reduce the Incidence of Medication Error

ORIGINALITY REPORT

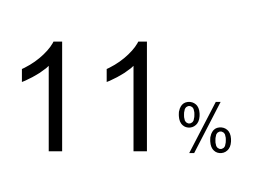

SIMILARITY INDEX

PRIMARY SOURCES

1 www.neliti.com Internet

96 words $-4 \%$

2 journals.plos.org Internet

65 words $-2 \%$

3 www.iaesjournal.com Internet

65 words $-2 \%$

4 pharm.kuleuven.be Internet

28 words $-1 \%$

5 scholar.uad.ac.id Internet 18 words $-1 \%$

6 portalgaruda.org Internet

12 words $-<1 \%$

7 iaesjournal.com Internet

10 words $-<1 \%$

8 ro.ecu.edu.au 